the initial activity made to appear by the grinding is unstable.

Tominaga KeII

TSUNEKaZU AKIYAMa

Department of Chemical Engineering,

Tokyo Institute of Technology, Meguro, Tokyo, Japan.

${ }^{1}$ Natta, G., and Pasquon, I., Adv. Catalysis, 11, 1 (1959).

${ }^{2}$ Keii, T., Nature, 196, 160 (1962).

\section{Some Interferometric Observations on the Water/Solids Relation of Activated Sludge Flocs, using a Compression Technique}

As part of a fundamental investigation of the water/ solids relation of activated sewage sludge an attempt was made to apply interference microscopy ${ }^{1}$ to the measurement of the solids content of the sludge floc.

The gelatinous consistency and irregular shape and size of the zoogloeal flocs have so far prevented any reliable estimate of the solids content of the flocs; such knowledge is of importance when investigating the behaviour of different sludges and may have a practical value in treatment plant design.

Since the calculations involved in the interferometric method required precise measurement of the thickness of the particles it was thought desirable to introduce some uniformity to the particles by compression. A cell com. pressor for the measurement of mass and concentration by interference microscopy has been described by Goldacre et al. ${ }^{2}$. We have found it more convenient to modify a Rousselets compressor to provide a compressed field by making a sandwich of the particles between two rubber cushioned cover-slips. For the type of material being examined this compressor has been found to be quite adequate, there being a relatively large area of compres. sion. The compressor is also suitable for immersion refractometry.

The glass disk is removed from the base of the Rousselets compressor and the cover-slip and its retaining clips removed from the upper plate. Two small strips of rubber are cemented to the bottom of the upper plate on either side of the aperture and a strip of cover-slip $7 \mathrm{~mm}$ wide is placed across the aperture and cemented to the strips of rubber. The hole in the base plate is enlarged and four strips of rubber are cemented to form a square about the hole.

A drop of suspension to be examined is placed on a hæmacytometer cover-slip supported by the strips of rubber on the base plate and the upper plate racked down. Initially the cover-slips are held together by the fluid between them. Further careful racking down of the upper plate results in the formation of the sandwich between the rubber cushions on the upper and lower plates.

The thickness of the compressed field can be found by conventional focusing methods making allowance for any slight variation across the width of the cover-slip.

Alternatively the thickness of the particle may be found by using the interferometric air-bubble technique ${ }^{3}$ or by calculating thickness from phase ehanges in immersion media of different refractive indices ${ }^{1}$.

Particles can be kept under observation during the com. pression process and they can usually be seen to flatten and spread out. The microscope adjustment is checked and adjusted when compression is complete.

Measurements are taken using a Baker half-shade eyopiece, and monochromatic light of $5420 \AA$ from a Didymium and Green filter.

In ealculating the results a value of 0.0018 has been assumed for $\alpha$ as the particles contain a large amount of protein.

The results obtained for three samples of activated sludge taken from a sewage works at different times are given in Table 1.

\section{Sample No.}

Table 1

Mean concentration of solids ( $\mathrm{g} / 100 \mathrm{ml}$. floc.) Mean concentration of water $(\mathrm{g} / 100 \mathrm{ml}$. floc.) Mean density
(1)

(2)

(3)
Unlike most cytological materials, activated sludge cannot be represented in terms of a typical structure and average particles dimensions, consequently it is not an easy material to examine. So far as is known this is the first time information about the in situ density and solids content of sludge floc has been presented.

Part of this investigation was supported by a research grant from Simon Carves, Ltd., Cheadle Heath, Stockport, Cheshire.

\section{P. Coackley}

Royal College of Science and Teehnology, Glasgow.

\section{B. KLIGER}

College of Science and Technology, Manchester.

1 Barer, R., The Interference Microscope in Quantitative Cytology (C. Baker. Holborn, Ltd., 1956).

${ }^{2}$ Goldacre, R. J., Easty, D. M., and Ambrose, E. J., Nature, 180, 1487 (1957).

${ }^{3}$ Ambrose, E. J., Proc. Roy. Soc., B, 148, 57 (1958).

\section{BIOCHEMISTRY}

\section{$\alpha$-Glycerolphosphate Production by Rat Hepatomas}

IT has been reported previously ${ }^{1}$ that the $\alpha$-glycerolphosphate dehydrogenase (L-glycerol-3-phosphate: $\mathrm{NAD}^{+}$ oxido-reductase, E.C. 1.1.1.8), either the crystalline form of the enzyme (Boehringer, U.S.) or that present in the post-mitochondrial fraction of rat liver and hepatomas, could be activated by potassium cyanide. At that time it was also found, although published only recently ${ }^{2}$, that potassium cyanide increased the anaerobic production of $\alpha$-glycerolphosphate (GP) from glucose-6-phosphate by the fortified post-mitochondrial fraction of three rat hepatomas.

Pette and Ruga ${ }^{8}$ have very recently demonstrated that potassium cyanide causes the dismutation of methyl. glyoxal. which contaminates the triosephosphate esters used as substrate in the enzyme assay, to pyruvate, which is then reduced by added $\mathrm{NADH}_{2}$ and the lactic dehydrogenase present in the post-mitochondrial fraction. These authors also obtained evidence for a non-enzymatic oxidation of $\mathrm{NADH}_{2}$ in mixtures of the triosephosphate esters, ethylenediamine tetraacetic acid and potassium cyanide.

Experiments carried out shortly after our first report ${ }^{1}$ was made cast doubt on the identity of the potassium cyanide effects obtained with the crystalline and postmitochondrial enzymes. Both the activity of the crystalline enzyme and the effect of potassium cyanide thoreupon varied, the two being inversely related; stimulation by potassium cyanide $\left(5 \times 10^{-4} \mathrm{M}\right)$ ranged from 30 to 200 per cent. In the latter cases the $\mathrm{NADH}_{2}$ oxidation by the crystalline enzyme was stimulated by EDTA $\left(10^{-2} \mathrm{M}\right)$ $<$ cysteamine $(10 \mu$ moles $)=$ potassium cyanide $=$ cyste amine plus potassium cyanide $<$ serum albumin $(0 \cdot 1$ per cent $)=$ hxmoglobin $(250 \mu \mathrm{g})=$ these proteins plus potassium cyanide. Using the post-mitochondrial liver fraction as enzyme source, eysteamine, EDTA and protein showed only a small effect $(20-30$ per cent increase of activity). However, the marked stimulation ${ }^{1}$ obtained with potassium cyanide and the post-mitochondrial liver and hepatoma enzymes was abolished by addition of cysteamine (even $0.5 \mu$ mole was effective). Another difference was apparent in the presence of $p$-chloromercuribenzoate (PCMB, $5 \times 10^{-5}$ and $10^{-4} \mathrm{M}$ ). The activity of the crystalline enzyme both in the absence and 